\title{
Condiciones y experiencias de trabajo en la sala de venta de un supermercado. Explorando los procesos de flexibilización laboral en el sector del retail en Chile*
}

\author{
Antonio Stecher \\ Universidad Diego Portales, Santiago, Chile. Email: antonio.stecher@udp.cl \\ Lorena Godoy
}

Centro de Estudios de la Mujer, Santiago, Chile. Email: lorena.godoycatalan@gmail.com

\author{
Juan Pablo Toro
}

Universidad Diego Portales, Santiago, Chile. Email: Juan.toro@udp.cl

Resumen: Este artículo presenta los resultados de una investigación de corte cualitativo realizada los años 2007 y 2008 en Santiago de Chile, la que tuvo como uno de sus objetivos el describir y comprender las condiciones y la experiencia de trabajo de un grupo de hombres y mujeres de bajo nivel ocupacional empleados en la sala de venta de una gran cadena nacional de supermercados. A partir de la presentación y discusión de estos hallazgos se busca contribuir a una mejor comprensión de los profundos procesos de flexibilización y modernización experimentados por el sector del retail en Chile en las últimas décadas, especialmente en lo que respecta al impacto de los mismos en la experiencia de trabajo de los sujetos empleados en dicho sector. Se espera de este modo arrojar luces desde una perspectiva psicosocial sobre los aspectos laborales de los cambios en el mundo del retail, los que han tendido a quedar invisibilizados ante los enfoques que han enfatizado las dimensiones económicas, o culturales y de consumo, de dichas transformaciones.

Palabras clave: Flexibilización laboral, Supermercados, Experiencias de trabajo, Retail, Chile

\section{Supermarket work conditions and experiences: An exploration of labor flexibilization in Chilean Retail}

Abstract: This article presents the results of a qualitative study done in 2007 and 2008 in Santiago, Chile. Its objectives were to describe and understand the work conditions and experience of a group of men and women with low occupational levels working on the sales room and at the checkouts of a large national supermarket chain. The presentation and discussion of our findings seek to contribute to a better understanding of the profound flexibilization and 
modernization processes experienced by the retail sector in Chile in recent decades, especially with respect to their impact on the work experience of the subjects employed in this sector. Thus, we take a psycho-social perspective in this attempt to shed light on the laboral aspects of changes in the retail world, which have been relegated to the background as other approaches have emphasized the economic, cultural, and consumption dimensions of these transformations

Retail, Chile

Key words: Labour flexibilization, Supermarkets, Working experiences,

\section{As condições de trabalho e experiências na área de vendas de um supermercado. Explorando os processos de flexibilização do trabalho no setor de varejo no Chile}

Resumo: Este artigo apresenta os resultados de uma pesquisa qualitativa realizada em 2007 e 2008, em Santiago do Chile, que teve como um de seus objetivos descrever e compreender as condições e experiência de trabalho de um grupo de homens e mulheres ocupacional dos trabalhadores de baixo nível no showroom de uma grande cadeia de supermercados nacionais. A partir da apresentação e discussão destes resultados é o de contribuir para uma melhor compreensão do relaxamento profundo e processo de modernização experimentado pelo setor de varejo no Chile nas últimas décadas, especialmente no que diz respeito ao seu impacto sobre experiência de trabalho de pessoas empregadas nesse setor. Esperase para lançar o modo de luz de uma perspectiva psicossocial sobre os aspectos de trabalho de mudanças no mundo do varejo, que tendem a ser invisíveis para as abordagens que têm enfatizado a econômica ou cultural eo consumo de tais mudanças.

Palavras-chave: trabalho flexível, supermercados, experiências de trabalho, Varejo, Chile

$$
* * *
$$

\section{Introducción}

El sector del retail en Chile -o comercio minorista o al detalle- ha experimentado en las últimas dos décadas importantes procesos de expansión y modernización, constituyéndose hoy en día en una de las áreas más competitivas y dinámicas de la economía chilena (Calderón 2006, Díaz, Ruiz Tagle, Aguilar y Frías 1999, Faiguenbaum, Berdegué y Reardon 2002) ${ }^{1}$. Una de las principales características de este proceso de reestructuración ha sido la progresiva concentración del negocio del retail en grandes grupos económicos (Cencosud, Falabella, D\&S, Ripley, La polar), con un fuerte peso de capitales nacionales, y con una apuesta por controlar y operar simultáneamente diversos tipos de negocio dentro del rubro: cadenas de supermercados, tiendas de departamento (multitienda), tiendas para el mejoramiento del hogar y locales especializados (Farmacias, materiales de construcción, etc.) (Durán y Kremerman 2008, Gálvez, Henríquez y Morales 2009, Lira 2005) ${ }^{2}$. 
El crecimiento de estos grandes grupos empresariales ha venido acompañado de un conjunto de nuevas tendencias dentro del sector. Se han implementado formas flexibles de gestión de los recursos humanos y de organización del trabajo, se han incorporado nuevas tecnologías y dispositivos de información y comunicación (software de gestión, control en línea de ventas y stocks, scanner en las cajas, etc.), y se ha profesionalizado la administración de las empresas (Calderón 2006, Lira 2005). Se advierte, a su vez, un crecimiento de los niveles de productividad a través del uso de economías de escala, la aceleración de la rotación de los productos y el control detallado sobre el ciclo completo del negocio; así como un crecimiento de los nichos de ganancia a través del desarrollo de marcas propias y de la oferta de líneas de crédito y servicios financieros para los clientes, especialmente aquellos de sectores sociales sin acceso a créditos bancarios (Calderón 2006, Geminis 1999). Otra tendencia es la internacionalización de las empresas del sector, las que se han insertado en las redes globales de comercio buscando los mejores productos al mejor precio, y las que han desarrollado agresivos planes de inversión y expansión en otros mercados regionales (Argentina, Perú, Colombia) (Calderón 2006). Por otro lado, se observa una ampliación de la cantidad, diversidad y calidad en la oferta de productos y servicios; una disminución de los precios al consumidor en el marco de una intensa competencia entre las grandes empresas; un fuerte despliegue de campañas publicitarias y de estrategias de marketing; así como el desarrollo de ofertas segmentadas y diferenciadas de consumo a partir del seguimiento detallado de los patrones de compra de los clientes (Calderón 2006, Du Gay 1996, Reardon y Berdegué 2002). Por último, se aprecia una política activa de apertura de nuevos locales por todo el país y en comunas de diferentes segmentos socioeconómicos -principalmente en el formato de grandes malls, multitiendas e hipermercados- así como una apuesta por una mejora continua en las instalaciones y la atención al cliente (mejores accesos, estacionamientos, luminosidad, climatización, seguridad, higiene, horarios de atención extendidos, promociones, tarjetas de cliente, etc.) (Lira 2005). Esta expansión a lo largo del país de grandes y modernos centros de venta ha jugado un rol importante en la disminución de los porcentajes de mercado de otras formas tradicionales de comercio minorista como la pequeña tienda, los kioscos, la feria popular y el antiguo almacén de barrio (Faiguenbaum, Berdegué y Reardon 2002, Lira 2005).

Este conjunto de tendencias observables en el escenario nacional, se inscriben, por cierto, en un marco mayor de procesos de reestructuración del negocio del retail a nivel global ocurridos desde fines de los años 80, los que han implicado el incremento del poder negociador y del peso relativo del capital de distribución frente al capital productor, y cuyo símbolo más emblemático es el crecimiento y expansión mundial de la cadena norteamericana Walt- Mart (Abal 2004, Ayus 2006, Bianco 2007). Por otra parte, esta reorganización del sector a nivel nacional y global debe ser entendida en el contexto más amplio de emergencia de una nueva matriz societal o fase de la modernidad caracterizada por un nuevo régimen de acumulación capitalista (global-informacional-flexible), la globalización cultural, la ampliación de los procesos de individualización, y la creciente 
importancia del consumo en las identidades y la vida cotidiana de los individuos (Bauman 1999, 2003, Beck 1998, 2000, Castells 2001, Garretón 2000, Lechner 2002, PNUD 2000, Wagner, 1997). Como han sugerido algunos autores, la imagen cotidiana de miles de consumidores comprando a crédito los variados productos y servicios que ofrecen los luminosos y vigilados pasillos de los hipermercados, da cuenta, no sólo de un proceso de reorganización de un sector económico específico, sino que se constituye en una poderosa metáfora, como lo fue antaño el obrero y la fábrica industrial, de las miserias y promesas del nuevo escenario tardo-moderno (Blanch 2003, Moulian 1998, Ritzer 1996).

Desde la perspectiva de los Estudios del trabajo este proceso de reorganización del retail en Chile resulta especialmente interesante pues las grandes empresas del sector se han caracterizado por implementar nuevos principios de gestión y diversas estrategias de flexibilidad laboral. Se observa, así, el uso tanto de formas de flexibilidad externa -contratos a plazo fijo, temporales, eventuales, externalización mediante subcontratación y/o suministro de personal- como de formas de flexibilidad interna -especialmente flexibilidad en la jornada de trabajo (contratos part time, jornada laboral escalonada, horarios nocturnos y de fin de semana) y en los sistemas de remuneraciones, pero también, aunque en menor medida, en lo que respecta a la implementación de innovaciones organizativas a nivel del proceso de trabajo: polifuncionalidad, círculos de calidad, equipos de trabajo, sistema justo a tiempo, descentralización del control, etc.) (Abramo, Montero y Reinecke 1997, Calderón, 2006, Echeverría y López 2004, Dirección del Trabajo 2009, Soto, 2008, Todaro y Yáñez, 2004). Con éstas diversas estrategias de flexibilización -las que se combinan en grados variables y con énfasis y modalidades diversas según las particularidades de cada empresa- la industria del retail ha buscado innovar y mejorar la calidad y eficiencia de los servicios ofrecidos, así como reducir costos laborales a través del ajuste permanentemente del tamaño de la fuerza de trabajo a las fluctuaciones de la demanda (Gálvez, Henríquez y Morales 2009, Dirección del Trabajo 2009) ${ }^{3}$. Si bien las grandes empresas del retail no representan en ningún caso la totalidad del comercio minorista, ni dan cuenta de la complejidad y heterogeneidad del actual mundo del trabajo en Chile, no es menos cierto que constituyen un empleador importante y un lugar privilegiado para indagar el modo como los procesos de flexibilización laboral -a nivel tanto de la estructuración del empleo como de la organización del trabajo- están impactando en las condiciones y experiencias de trabajo de hombres y mujeres empleados en grandes empresas del sector servicios ${ }^{4}$.

En este marco, el presente artículo da cuenta de una parte de los resultados de una investigación de corte cualitativo realizada los años 20072008 en Santiago de Chile con trabajadores de bajo nivel ocupacional de una gran cadena nacional de supermercado ${ }^{5}$. Se trata, específicamente, de la presentación de aquella parte de los resultados relativa a las condiciones y la experiencia de trabajo de esta muestra de sujetos. Nuestro interés es tratar de reconstruir algunos aspectos de la cotidianidad laboral de un grupo de empleados de la sala de venta de un supermercado, intentando 
visibilizar -desde la perspectiva de los propios trabajadores- lo que significa trabajar en una gran empresa de la industria del retail que ha hecho suyas las nuevas lógicas gerenciales de administración de los recursos humanos y de organización del trabajo. A partir de la presentación y discusión de estos hallazgos esperamos contribuir - desde un enfoque psicosocial interesado en recuperar los relatos y las experiencias de los sujetos que trabajan- a una mejor comprensión de la dimensión laboral del mundo del retail en Chile. Esta ha tendido a quedar en un segundo plano ante las perspectivas que han enfatizado los aspectos e indicadores económicos, o las implicancias culturales y de consumo, de los procesos de reorganización del sector. Más ampliamente y en continuidad con la reflexión iniciada en investigaciones anteriores, el artículo busca ser un aporte en la necesaria tarea de seguir explorando críticamente las dimensiones psicosociales (experiencias, cotidianidad, significados, sociabilidad, identidades, riesgos, bienestar y malestar, etc.) de los procesos de reorganización productiva y flexibilización del mercado laboral que han transformado en las últimas décadas el mundo del trabajo en Chile (Díaz, Godoy, Stecher y Toro 2006, Díaz, Godoy y Stecher 2005, Godoy, Stecher, Díaz 2007, Godoy y Stecher 2008, Stecher, Godoy y Díaz 2005).

\section{Metodología}

La investigación utilizó una metodología cualitativa enmarcada en una perspectiva crítico-interpretativa (Thompson 1990). La información fue producida a través de diversas técnicas que permitieron complementar y enriquecer la descripción y análisis del fenómeno en estudio. Se realizaron 20 entrevistas individuales semi-estructuradas a trabajadores de una cadena de supermercados, y 3 entrevistas a informantes claves (del mundo empresarial, del sector público y del mundo sindical), especialistas en el desarrollo y los cambios del retail en Chile. Además, a lo largo de 2 meses se efectuó una observación no participante de una sala de venta de un local de Santiago que pertenecía a la cadena de supermercados en que se desempeñaban los trabajadores entrevistados.

Respecto a los trabajadores participantes del estudio fueron 20 empleados de bajo nivel ocupacional (operarios, vendedores) que se desempeñan en las salas de venta de distintos locales de Santiago de una de las grandes y modernizadas empresas nacionales de supermercados. La muestra fue no representativa y de tipo intencional opinático (Ruiz, 1993), e internamente diferenciada según los siguientes criterios previamente definidos: género, secciones de trabajo dentro de la sala de venta, edad, relación contractual y participación sindical. De acuerdo con estos criterios se entrevistó a 10 hombres y 10 mujeres, de los cuales 3 (mujeres) trabajaban en la sección de cajas, 1 (mujer) en información, 5 ( 2 mujeres y 3 hombres) en reposición, 2 (mujeres) en aseo, 2 ( 1 mujer y 1 hombre) en fiambrería, 2 (hombres) en carnicería, 3 ( 1 mujer y 2 hombres) en panadería y 2 (hombres) en vegetales. Respecto de sus edades, 6 entrevistados tenían menos de 30 años (3 mujeres y 3 hombres); 10 entre 30 y 50 años (6 mujeres y 4 
hombres); y 4 tenían 50 años y más (1 mujer y 3 hombres). En cuanto a la relación contractual, 13 entrevistados eran de planta y jornada completa (5 mujeres y 8 hombres), 4 eran trabajadores externalizados de empresas subcontratistas ( 3 mujeres y 1 hombre), 1 trabajador estaba contratado jornada completa pero por plazo fijo (1 hombre) y dos trabajadoras eran part time de 30 horas. En relación con la participación sindical, ocho mujeres y seis hombres estaban afiliados.

El material empírico fue analizado a partir de los procedimientos del análisis de contenido de orientación cualitativa (Ruiz, 2003), buscando reconstruir, a través de procesos sucesivos de lectura, categorización, organización y re-contextualización teórica de la información (Huberman y Miles 1994), las significaciones, prácticas y condiciones que caracterizan la experiencia cotidiana de un grupo de trabajadores al interior de un supermercado.

\section{Presentación y discusión de resultados}

En este apartado presentamos tres ejes que dan cuenta de algunos aspectos relevantes de las condiciones, la cotidianidad y la experiencia laboral del grupo de trabajadores estudiado ${ }^{6}$. Como hemos señalado, se trata de empleados de bajo nivel ocupacional que se desempeñan en la sala de venta de una importante cadena chilena de supermercados, la que participa de las distintas tendencias de modernización del sector del retail a las cuales nos hemos referido, incluyendo la adopción de diversas estrategias de flexibilidad laboral ${ }^{7}$.

\section{Las secciones como anclajes de la experiencia de trabajo: diferenciación y desigualdad}

Uno de los hallazgos del estudio fue la constatación del modo en que la sala de venta de un supermercado es un espacio internamente diferenciado, donde las diversas secciones operan como micro mundos y particulares anclajes de la cotidianidad laboral. En efecto, un elemento central de la organización del trabajo es la división (espacial, funcional, simbólica) por secciones (verduras, cajas, carnicería, panadería, reponedores de sala, fiambrería, pescadería, aseo, etc.), cada una de las cuales conlleva ciertas especificidades a nivel de las condiciones y experiencias de traba$\mathrm{jo}^{8}$. La pertenencia a una u otra sección de la sala de venta supone para los trabajadores diferencias importantes a nivel de las funciones, el estatus, el salario, los uniformes, el grado de interacción con clientes y jefaturas, los niveles de autonomía y control respecto a la tarea, las posibilidades de movilidad, la ubicación en el espacio, la interacción con la tecnología, el carácter "femenino" o "masculino" de la actividad desempeñada, los grados de reconocimiento social dentro y fuera del supermercado y el tipo de identidad laboral. 
En ese marco se observó que el puesto de cajera -fundamentalmente mujeres jóvenes, muchas de ellas part time- se caracteriza por la presión constante de los clientes y sus jefaturas, la polifuncionalidad, la inmovilidad, la baja autonomía, el fuerte control y la falta de reconocimiento. Los reponedores (mayoritariamente hombres jóvenes) en conjunto con los equipos de aseo (personal subcontratado mayoritariamente femenino) constituyen grupos de trabajadores que se caracterizan por una alta movilidad al interior de la sala de venta, y por tener, junto a las cajeras, los niveles más bajos de formación y reconocimiento. A diferencia de las cajeras, sin embargo, no desarrollan atención al cliente y tienen mayores posibilidades de desplazamiento, lo que redunda en una relativa autonomía. Quienes laboran en estas tres secciones constituyen el sector de trabajadores más precarizado, que goza de menor reconocimiento y de peores condiciones de trabajo dentro de la sala de venta ${ }^{9}$. Carnicería, panadería, pescadería y fiambrería constituyen las áreas de mayor prestigio al interior del supermercado, en términos de la valoración social de sus labores, de sus niveles de calificación, de la autonomía y control sobre el trabajo, lo que se refleja también en niveles más altos de satisfacción y remuneración. En estas secciones se mantiene el imaginario de "la identidad de oficio", donde los empleados, mayoritariamente hombres de mediana edad, son "maestros" expertos en sus funciones. Los operarios de verdulería desempeñan sus funciones de manera bastante independiente, con importantes márgenes de autonomía y con posibilidades de desplazamiento entre la bodega en que se almacenan los productos y el punto de venta y atención al cliente. Se trata de una sección de carácter más bien masculino, que en términos de estatus, prestigio, reconocimiento y autonomía se ubica en un nivel intermedio, entre el polo más precarizado de cajeras, reponedores y aseadoras, y el más calificado de los "maestros”.

Es posible ilustrar con mayor detalle esta heterogeneidad de las condiciones y experiencias de trabajo, de la cual son plenamente conscientes los trabajadores, a partir de la comparación entre la situación de las cajeras y la del grupo de los "maestros" carniceros, fiambreros, panaderos, pescaderos.

El puesto de cajera -un cargo que en el supermercado estudiado era casi exclusivamente femenino, con un alto porcentaje de personal joven part time (cerca del 50\%)- tiene como función principal la atención a los clientes al final de su compra, marcando y cobrando en las cajas registradoras el valor de los productos adquiridos. Las cajeras sufren una fuerte presión por parte de los clientes, quienes suelen descargar en ellas su molestia por las filas o su inconformidad con cualquier situación producida durante su compra. Al mismo tiempo, y debido al manejo del dinero, las cajeras están sometidas a una fuerte vigilancia por parte de sus supervisoras. Esa presión constante de clientes y supervisoras se vive con particular intensidad y se asocia a grados importantes de malestar debido a un conjunto de aspectos tales como: la imposibilidad de moverse que supone el puesto -deben pedir autorización para ir al baño o salir de su caja-, los bajos niveles de autonomía y de control sobre el trabajo realizado -el pro- 
ceso de registro, cobro y de interacción con los clientes está estandarizado, y deben pedir autorización para una serie de procedimientos tales como devoluciones, anulaciones, cambios de producto, arqueos manuales-, la dificultad de conversar, interactuar y recibir apoyo de parte de sus compañeras mientras están en sus posiciones, el fuerte desgaste físico que supone estar en la misma posición durante largas horas -muchas veces en sillas incomodas o defectuosas-, la exigencia de trabajo emocional propia del sector servicios -establecer activamente un vínculo cercano, cordial y atento con los clientes (Leidner 1999, Macdonald y Sirianni 1996)-, la dependencia y poco control respecto a los sistemas tecnológicos asociados al pago de los clientes (escáner de precios, caja, tarjetas de crédito), así como la carga que supone asumir diversas funciones anexas a la del cobro mismo: oferta de promociones, solicitud de donaciones, carga de puntos de tarjeta de cliente, orden de anaqueles cercanos, limpieza de cinta transportadora, eventuales apoyos en el empaque, etc.

Los relatos de las cajeras dan cuenta, así, de un trabajo muy intenso y agotador, particularmente en las horas y fechas de más clientes. Algunas de ellas señalan haber pensado solicitar un cambio de puesto a alguna otra sección con una menor carga de trabajo, o, en el caso de las cajeras part time más jóvenes, dejar el empleo en cuanto tengan una mejor oportunidad laboral. Un testimonio permite ilustrar lo señalado:

Un trabajo exigente, exigente y cansador psicológicamente. Te exigen por ejemplo estar con la cara sonriente y siempre amable, y cansador en el sentido de los clientes que siempre pelean por todo, por los precios... En ese sentido es un poco chocante, es preferible estar en otras secciones en vez de las cajas porque nosotros somos como se dice el rostro de la empresa, porque todo lo que sale pasa por las cajas y uno tiene que estar ahí sonriendo "buenas tardes, buenos días” y que estar y poner la cara, porque todo lo malo de adentro se desquitan con la cajera siempre, "la cajera tiene la culpa”, "la cajera me cobró mal”, "la cajera se equivocó con los precios"... es agotador(...) yo incluso (...) he hablado dos veces con el Gerente que me he querido cambiar de sección; por ejemplo, para la Navidad y el año Nuevo fue espantoso, (...), hasta las 12:00 de la noche atendimos, desde las 8:00 de la mañana hasta las 12: 00 de la noche abierto el local, la gente pasaba los carros llenos, no podías ir al baño aunque quisieras, te daba cosa, yo creo que terminabas con una úlcera nerviosa, me dolía la guata estar ahí todo el día. (...) Por la cantidad y la presión de ver las filas, las filas llenas, ver hasta el final, casi la mitad del supermercado con las filas, tenías que seguir atendiendo, las tarjetas, que a veces se va el sistema, no hay línea, nerviosa, la gente empieza a silbar a gritar "apúrense”, “contrate más cajeras” y cosas así, es como súper estresante (Cajera, part time, 25 años)

A estas exigentes condiciones de trabajo se suma la falta de valoración que perciben las cajeras respecto al rol que desempeñan. Se trata de un 
puesto con una remuneración apenas por sobre el salario mínimo, con frecuente rotación de personal -particularmente en las cajeras part time-, con escasas instancias de capacitación, y con un bajo reconocimiento del trabajo que realizan por parte de la empresa, los clientes, los empleados de las otras secciones - que las describen como trabajadoras que "no se ensucian ni las manos", que "no hacen nada", que "están sentadas"- y la sociedad en su conjunto. Así, los relatos de las cajeras dan cuenta además de las duras condiciones objetivas- de un malestar subjetivo producto de la falta de reconocimiento por el trabajo realizado, de un anhelo porque se respete y otorgue dignidad a la función que desempeñan, dejando de ser consideradas como un recurso barato, "multiuso" y fácilmente reemplazable.

Para toda la gente somos empleados no más. Somos empleados..., incluso como dije en un principio creo que este trabajo es súper humillante. (...)Yo creo que a nadie le gustaría mucho ser cajera (...) y en el supermercado en general, yo creo que es harto el trabajo. Y que a veces no, no es reconocido. No es reconocido por nadie, ni por la gente que está ahí ni por la gente de afuera y eso es lo fome. Es súper triste que no sea reconocido el trabajo, porque es harto (Cajera, part time, 27 años)

El caso de los “maestros” panaderos, fiambreros, carniceros, pescaderos constituye el polo opuesto a la situación de las cajeras. Se trata de un grupo de trabajadores, por lo general hombres de mediana edad, con contratos indefinidos y jornada completa. Ellos desempeñan oficios de marcada identidad, poseen una formación y/o una larga experiencia en la función que desempeñan, están a cargo de alimentos perecibles y tienen las condiciones de trabajo más favorables dentro del grupo de empleados de bajo nivel ocupacional del supermercado. Este grupo de trabajadores cuenta con los mejores salarios dentro de la sala de venta (hasta dos sueldos mínimos), así como con un mayor estatus y reconocimiento por parte de la empresa, los clientes, los compañeros y la sociedad. Un entrevistado que trabajó mucho tiempo en la sección de pescadería indica:

...tenía 43 años de experiencia (en pescadería) cuando me presenté. (...) Llegué allá, me presenté y el administrador hizo llamar a la encargada de Deli, y esa muchacha me vio y me dijo -a todos se los trata de maestros-, "maestro, menos mal, lo estamos esperando hace tanto tiempo", (...) estaba en mi salsa en la pescadería, no es por nada, pero yo llegué a enseñarle a los chiquillos que estaban ahí, sabían, pero lo básico no más; de partida no sabían guardar la mercadería, la dejaban en la cámara de carnicería y eso no sirve porque el pescado tiene que ir directamente con hielo porque el hielo es lo que lo mantiene, no una cámara, porque la cámara lo quema, la luz, la electricidad lo quema, lo pone amarillo; (...). Así que ahí empecé a enseñarles (...). Así empecé a tener clientela, me decían, "nosotros no venimos por esto y por esto, se ve que está cambiando porque hay de todo, antes vendían lo básico, que era la pescada y el 
jurel no más”; yo no, empecé a pedir de todo, me dieron la autorización para que yo hiciera el pedido, con la experiencia que tenía (Operario de vegetales, jornada completa, 55 años)

Este testimonio ilustra el valor simbólico que supone la identidad de oficio y da cuenta de una experiencia y de condiciones de trabajo bastante más favorables en comparación a lo señalado para el caso de las cajeras. Ello porque se trata de trabajadores a quienes se les reconoce como poseedores de un saber experto, especializado, en el cual se es "maestro"; que tienen la posibilidad de enseñar a otros y capacitarlos en ese saber; que obtienen valoración y reconocimiento público del trabajo que desempeñan; que en el ejercicio de sus funciones cuentan con importantes grados de control y ciertos márgenes de autonomía para la toma de decisiones; que tienen posibilidades de desplazamiento (fábrica de pan, bodegas, frigoríficos), lo que supone un menor sometimiento a la vigilancia directa de las jefaturas y a las exigencias permanentes de los clientes; que pueden más fácilmente dotar de un sentido positivo la experiencia laboral a partir de un sentimiento y experiencia cotidiana de ser competente, de ser reconocido y de estar haciendo aquello que uno domina y le gusta.

En este grupo de trabajadores -si bien existen quejas respecto al nivel de remuneraciones, a ocasionales maltratos, a la carga y los horarios de trabajo- predomina la satisfacción con su trabajo, la identificación con el oficio y una alta motivación y deseo de realizar bien sus funciones.

Yo soy maestro carnicero, llevo treinta años en el supermercado trabajando (...) Es que es lo mío, yo he sido carnicero toda mi vida. Soy hijo de carnicero (...). Me gusta mucho lo que hago (...). Tuve la posibilidad de trabajar con muy buenos maestros, me enseñaron harto y a la vez yo siempre he sido agradecido de ellos, de lo que me enseñaron. Incluso mucha gente dice que yo he sido, que fui un buen alumno para todos, porque aprendí de todo. Aprendí la rapidez de ellos, tuve la rapidez...gallos que se demoraban menos de un minuto en desarmarse una pierna. Llegué a participar con ellos, a echar carreras cortando y me gustó. Y todo lo que hago en el surtido de carnes me gusta, me gusta meterme en la máquina de cortar huesos y me gusta a pesar que tengo dos cortes en la máquina de cortar huesos, me gusta estar ahí (Operario de carnicería, jornada completa, 48 años)

[estoy contento] de hacer bien mi trabajo, simplemente hacer lo que hay que hacer, haciendo mi pega durante mis siete horas y media está todo bien, todo tranquilo, llego feliz a mi casa, contento de la vida, no tengo nada de qué quejarme, yo sé que no estoy ganando un sueldo de un millón, pero sé que a una persona que hace aseo le pagan el mínimo y gano mucho más que él y estoy feliz, contento, no puedo pedir más a la vida, a la vida le debo yo (Operario pastelería, jornada completa, 34 años) 
De este primer eje de caracterización nos parece importante destacar dos elementos. En primer lugar, las importantes diferencias a nivel de condiciones y experiencias de trabajo entre trabajadores de un nivel jerárquico similar dentro de una misma empresa. Los hallazgos dan cuenta de cómo la pertenencia a particulares secciones supone -para trabajadores equivalentes y situados en un mismo espacio físico y organizacional- formas de trabajo muy distintas. Esto plantea la exigencia de desarrollar investigación empírica capaz de atender y relevar los modos diferenciados y específicos en que las nuevas formas de organización flexible del trabajo impactan en distintos sujetos laborales. En esa línea, resulta fundamental atender a los procesos de reproducción de las desigualdades de género dentro de los emergentes espacios laborales del sector comercio, los que implican -como lo ilustra el contrapunto presentado entre las cajeras y los maestros- que en los puestos con menores niveles de autonomía, mayor exigencia emocional y condiciones más precarias, tiendan a predominar las mujeres (De Oliveira y Ariza 2000, Todaro y Yáñez 2004). En segundo lugar, el modo en que en una gran empresa modernizada conviven elementos del paradigma productivo taylorista-fordista junto a nuevas tecnologías y formas flexibles de gestión de la mano de obra y organización del trabajo ${ }^{10}$. Así, por ejemplo, el puesto de cajera se caracteriza, por un lado, por altos niveles de control y vigilancia directa, escasa autonomía y control sobre el trabajo, alta formalización y estandarización de las actividades, prevalencia de las funciones de ejecución y ausencia de las funciones de concepción, tareas mecánicas y repetitivas, mantenimiento de una posición fija frente a una "máquina” (correa transportadora, escáner y caja) que establece en gran medida los ritmos del trabajo, y débil apropiación e identificación con la cultura y valores de la organización. Pero, por otro lado, dicho puesto se caracteriza también por la incorporación de formas flexibles de empleo y por la presencia de diversas innovaciones organizativas a nivel del proceso de trabajo y de producción: Exigencias de polivalencia, responsabilización individual de la gestión (cada cajera asume y se hace responsable del arqueo de su caja y debe responder individualmente por cualquier falta de dinero al final del turno), incremento de la carga mental (altas demandas de atención y concentración debido a la interacción con la tecnología y las diversas posibilidad de pago de los clientes), exigencias de implicación subjetiva y trabajo emocional (las cajeras deben desarrollar competencias relacionales e implicarse afectivamente en el vínculo con los clientes), intensificación del trabajo en el marco estrategias de lean production (reducción de tiempos muertos y gestión del recurso humano por parte de la empresa que hace que las cajeras estén siempre con la máxima demanda de trabajo posible), flexibilidad (unilateral) de la jornada, presencia de formas atípicas de contrato que suelen incidir en una precarización del empleo (bajos sueldos, inestabilidad laboral, pérdida de beneficios), entre otros.

Esta combinación de principios tayloristas-fordistas junto a otros vinculados a los nuevos modelos productivos (Especialización flexible, Toyotismo, Kalmerismo, etc.) está presente con mayor o menor intensidad en los trabajadores de las diferentes secciones de la sala de venta del super- 
mercado, y es uno de los aspectos distintivos de su experiencia y cotidianidad laboral. Como en el caso de las cajeras esa combinación puede significar la articulación en un solo puesto de los aspectos más negativos del modelo taylorista-fordista y de la flexibilidad laboral, o puede, como en el caso de los maestros -donde la relación laboral normal y la pertenencia a una identidad y estatuto colectivo vinculado al oficio coexiste con ciertos grados de autonomía, trabajo en equipo e identificación con el servicio al clienteadquirir formas relativamente más virtuosas o menos precarizantes.

\section{Exigencias de polifuncionalidad, débil control del tiempo e intensificación del trabajo}

Un segundo eje que caracteriza transversalmente la cotidianidad del grupo de trabajadores entrevistados dice relación con las exigencias de polifuncionalidad, el escaso control sobre la jornada laboral y la intensificación del trabajo, aspectos que han sido ampliamente descritos por la literatura como rasgos importantes de las nuevas formas de organización y gestión del trabajo (Blanch 2003, Boltanski y Chiapello 2002, Garrido 2006, Goudswaard y Nanteuil 2000, Gospel 2003, Neffa 2003, Smith 1997).

En los distintos relatos emerge la figura del trabajador como un recurso polifuncional que debe estar siempre listo y dispuesto para responder a las diversas demandas de la empresa. Esto está sancionado legalmente en muchos de los contratos, donde se explicita que el supermercado puede ocupar la fuerza de trabajo de un sujeto en distintas tareas de la sala de venta. Así, por ejemplo, el contrato de las cajeras señala que son reponedorasvendedoras-cajeras, lo que permite a la empresa ubicarlas en distintas posiciones según las fluctuantes demandas (en el día, la semana o el año) de trabajo y la disponibilidad de trabajadores. Los usos que hace la empresa de la polifuncionalidad son muy variados y buscan dar respuesta a requerimientos muy diversos, pudiendo ir desde la cobertura puntual que hace un empleado de otra posición de trabajo durante el período de colación del responsable de dicha posición, a cambios más permanentes (meses o años) entre distintas secciones, pasando por los reemplazos y coberturas de uno o más días con los que la empresa afronta las situaciones de ausentismo y rotación de trabajadores.

Yo he estado (cubriendo) en panadería, fiambrería, deli, pescadería, vegetales y abarrotes. He estado en todo, menos en caja. Una, porque faltan. Segundo, que contratan pura gente nueva, part time que van los fines de semana. Llegan perdidos, no se saben los precios, los códigos.(...) Yo ya llevo cinco años en el supermercado, entonces ya me conozco todos los precios, los códigos (Reponedor de planta, jornada completa, 29 años)

A veces también trabajo como reponedora de las "gancheras". (...) Sí, a veces, cuando hay muchas cajeras la jefa lo pide y hay que 
limpiarlas, reponerlas, cambiar los flejes (...) a veces también, yo por lo menos, he tenido que ir a la sección de panadería o vegetales, a pesar pan o frutas y verduras, cuando hay gente que ha faltado. (...) Es muy de vez en cuando, pero siempre piden una cajera. Aunque no en fiambrería, o en la sección de deli. Ahí no nos podemos incluir porque no sabemos. Pero sí en lo que es pesar pan o verduras, casi siempre a esos dos lados sí (Cajera, jornada completa, 25 años).

Este último testimonio da cuenta de que la polifuncionalidad es más factible cuando se trata de los empleados menos calificados y del desarrollo de tareas que no requieren mayor capacitación. Una cajera o un reponedor, además de sus funciones básicas, puede hacer un poco de limpieza, reemplazar a alguien en una pesa de panadería y verdulería, traer los carros del estacionamiento, pero no puede cumplir funciones más especializadas como las de trabajar en la preparación o corte del pan, las carnes, el pescado o las cecinas. En cambio, los cargos más calificados, los puestos de oficio a cargos de los "maestros", tienen expresamente prohibido el asumir funciones distintas a las asignadas, siendo así muy difícil ver a un panadero en el punto de venta de la sección.

Pero a veces ha faltado una persona porque no vino, porque faltó por algo, y como los panaderos no pueden vender, entonces le piden a una persona (de cajas).... (Vendedora Panadería, jornada completa, 48 años)

Así, la polifuncionalidad dentro de la sala de venta, asociada generalmente a los trabajadores menos calificados, no es experimentada como una posibilidad de formación y enriquecimiento del empleo a partir de nuevas y desafiantes tareas, sino como una intensificación del trabajo, una degradación y falta de reconocimiento de las funciones específicas, una expresión del poder de la empresa para disponer unilateralmente de los empleados en función de los objetivos del negocio. Muchos entrevistados señalan que han vivido experiencias desagradables cuando los supervisores los envían sorpresivamente y sin la información adecuada a ocupar otros puestos de trabajo, y que sienten que al hacer eso la empresa no está reconociendo la especificidad y especialización que demanda su puesto habitual.

...porque me han mandado a pesar el pan, de repente, dicen: “ $i$ Ay, sabes que no hay nadie en panadería, así que cierra tu caja y pesa el pan!” Y eso también es lo que me ha molestado. Por ejemplo, una vez me mandaron a la verdulería, me mandaron, me dijeron: “¡Ya, vaya a vegetales!” Y yo no sabía ocupar la máquina... “iAy, pero cómo no va a saber!”...Me retaron más encima. Y una señora me preguntó cuánto costaban las naranjas y yo le dije: “A ver, espere”..., y no tenían precio, entonces yo no sabía a quién preguntar y la señora hizo un escándalo. (...) (Cajera, part time, 27 años). 
Junto a la polifuncionalidad, los entrevistados mencionan el control sobre los tiempos del trabajador por parte de la empresa como otro elemento que define su experiencia de trabajo. Para los empleados de la sala de venta trabajar en el supermercado supone poner sus tiempos, laborales y extralaborales, al servicio de los cambiantes requerimientos de la empresa. Esta dispone, controla y cambia de forma bastante arbitraria (semanal o mensualmente) los turnos (mañana o tarde), lo días de descanso durante la semana, e incluso las vacaciones ${ }^{11}$.

Estas formas de control del tiempo son una de las expresiones más claras de la asimetría y de la unilateralidad que caracteriza -especialmente en el caso de los trabajadores de bajo nivel ocupacional- el modo como se han implementado en muchas grandes empresas de nuestro país las formas de organización y gestión flexible, con las que se ha buscado ajustar, sin ninguna consideración, los tiempos del trabajador a los requerimientos de la empresa (Reinecke 2006). Como los horarios, que ya son flexibles (turnos distintos según días, trabajo fin de semana y hasta las 23 horas), pueden cambiar, los trabajadores encuentran muchas dificultades para comprometerse y desarrollar otras actividades extralaborales, pues sus horas libres pueden pasar a ser horas de trabajo de un momento a otro.

Incluso, no me gusta (trabajar fines de semana). Es que resulta que yo el domingo vendo en la feria, siempre, todos los domingos. Y cuando hicieron este cambio (de horario), a mí me complicó mucho y yo decía: "Pucha, en vez de tener más plata voy a tener lo mismo y voy a tener que trabajar domingo". Entonces, fui a hablar con el gerente y él me dijo: "Bueno, haga lo que quiera, si quiere se va". Me dijo eso, y yo al principio me puse a llorar... (Cajera, part time, 27 años).

Si bien existen casos de trabajadores que han logrado acuerdos horarios estables y favorables con sus supervisores, lo que predomina en los entrevistados es la experiencia de que están sometidos a la voluntad de la empresa, y que ésta tiene, en última instancia, el poder de fijar y cambiar arbitrariamente sus turnos de trabajo. Así, y al igual que en el caso de la polifuncionalidad, la flexibilidad temporal es percibida en este grupo de trabajadores de bajo nivel ocupacional, más que como un símbolo de trabajo moderno y una oportunidad de mayor autonomía y calidad de vida, como un instrumento de explotación y precarización a favor de los intereses de la empresa.

Por último, respecto a la intensificación del trabajo, en las entrevistas se observa una tendencia a la eliminación de las pausas de trabajo, una presión permanente de las jefaturas para que los trabajadores estén siempre ocupados, para convertir cada minuto en un minuto productivo, de tal modo de poder cubrir con menos dotación de personal las demandas de funcionamiento del local. Como nos señala una cajera part time, que trabaja en turnos de 5 o 10 hrs diarias: 
En un día normal vendo de 500 mil a 700 mil pesos; la colación es de 15 minutos, cuando uno quiere ir al baño pide permiso; está relativamente lleno, todo el día, toda la jornada, las 5 horas estamos atendiendo a cada momento (Cajera, part time, 25 años).

Otro entrevistado señala cómo ante el menor tiempo libre se le exige nuevas tareas, aunque sean innecesarias o inútiles, pues por principio un trabajador de supermercado no puede estar nunca en una posición de descanso.

Uno a veces no puede ni estar un rato parado, ... viene el jefe y si hay algo limpio dice igual que lo limpie, estando limpio, usted ve un jefe que viene y tiene que pescar algo y hacer así (frota un paño), para que lo vea haciendo algo, eso lo encuentro injusto porque si está limpio cómo lo va a limpiar de nuevo, no lo pueden ver parado y le exigen, que aquí, que allá. (...) Ellos saben lo que uno hace porque lo están mirando a uno, lo tienen visto por todos lados, uno no puede estar parado, menos sentarse, está prohibido, por lo menos en el local (Operario de vegetales, jornada completa, 55 años)

\section{La responsabilización individual como estrategia de control}

Un tercer aspecto que caracteriza la experiencia y la organización del trabajo en la sala de venta es el fuerte despliegue por parte de la empresa de diversas estrategias de evaluación y responsabilización individual de los trabajadores. A través de diversos mecanismos de registro la empresa controla y hace un seguimiento permanente del desempeño individual de cada empleado, retroalimentándolos constantemente en función del nivel de cumplimiento de las metas establecidas y del rendimiento comparativo de sus compañeros.

Dichos dispositivos de monitoreo individualizado van acompañados de un conjunto de discursos propios del new management ${ }^{12}$ que ensalzan y hacen del emprendimiento, competitividad, identificación con los valores de la empresa, iniciativa y esfuerzo individual de cada trabajador la clave del éxito o fracaso económico de la organización, a cuya suerte estaría ligada la estabilidad laboral y el bienestar económico de los trabajadores (Boltanski y Chiapello 2002, Hirsh y De Soucey 2006, Sennett 2006, Soto 2008). Así, cada trabajador es interpelado desde la empresa como sujeto individualmente responsable, en todo sentido y en todo momento, de los logros o fracasos en el desempeño de su función. Siguiendo a Martuccelli (2007) es posible plantear que no es sólo que el trabajador sea responsable de todo lo que hace, sino que es responsabilizado individualmente de todo lo que acontece en su puesto de trabajo cuando él está a cargo, independientemente de la injerencia efectiva que él haya podido tener en lo sucedido. Un caso ejemplar al 
respecto es la relación de las cajeras con “sus cajas”, las cuales deben abrir, contabilizar, cerrar, y en caso de pérdidas, reponerles el dinero. Esto genera muchas veces ansiedad en ellas, pues al final de cada turno se enfrentan con temor a la posibilidad de que la caja no cuadre. Al respecto, una entrevistada relata:

Una vez me faltó 2000 mil pesos y me los han descontado, pero son pocas veces porque igual yo estoy súper concentrada como son poquitas horas, (...), porque igual es un poco incómodo que te descuenten de tu sueldo aunque sea 5 pesos o 10 pesos es plata (Cajera, part time, 25 años)

Esta lógica de la responsabilización individual lleva a que incluso las cajeras se refieran a la plata de sus cajas como "mi plata", en tanto ellas, y no la empresa o la supervisora o el colectivo de cajeras, son responsables de la misma.

Por ejemplo yo ayer tenía 70 mil pesos en billetes de a mil, y la jefa me retó y me dijo: “¡Pero cómo podís tener...!”...Bueno es plata que me dieron no más, y empecé a contarla... “¡Más encima la vai a contar así, dos veces!”... “Obvio po, si es mi plata”. Y estaba súper enojada, porque yo estaba contando la plata. Ellas se enojan mucho, pero es mi plata y yo la tengo que contar... (Cajera, part time, 27 años).

Este principio de la responsabilización individual opera desde el momento que se ingresa a trabajar al local. En muchos casos los trabajadores no reciben una capacitación formal sino que son puestos a observar el trabajo de empleados más antiguos, recayendo en ellos mismos la responsabilidad de autoformarse. El mensaje parece ser que cada trabajador es un agente a cargo de una "unidad de producción” y que es su responsabilidad, no de la empresa, el formarse, el mantenerse actualizado, el incrementar constantemente su eficiencia y productividad, y el responder adecuadamente ante las demandas de los clientes, de otros compañeros y de las jefaturas, debiendo hacerse responsable, incluso pecuniariamente, ante cualquier fallo en ese proceso de autoformación y ejercicio de su puesto. Como señala una cajera, dando cuenta de su (auto) capacitación al ingresar a la empresa y del desamparo que este proceso muchas veces supone:

Yo entré y me dijeron: "Su compañera le va a ayudar”. Y mi compañera me dijo: "Siéntate ahí y atiende". Y yo no sabía nada de teclas, yo Oooooh, porque era súper distinto a los otros trabajos que tuve (...). Y ella me iba explicando y entre que me iba explicando, lo único que ella se preocupa igual era que yo no fuera a perder su plata, pero era eso...Y a los dos o tres día ya estaba sola en una caja y oh, no me quería ni equivocar, ojalá que no me salga un cheque, decía yo, por favor un cheque no. Todo eso era terrible, porque aprender que lo pagos, pago $\mathrm{N}$, que ahí siempre se paga la tarjeta $\mathrm{N}$, que las tarjetas de crédito, que si pierdo un voucher, que la firma, de repente, no sé o el cheque (Cajera, part time, 27 años) 
Para este grupo de trabajadores la responsabilización individual es experimentada fundamentalmente como una coerción y una amenaza, y no tanto como la posibilidad de construir una nueva identidad y práctica laboral significativa y reconocida por la empresa en torno a los valores del emprendimiento, la autonomía, la identificación con la organización y el desarrollo de nuevas competencias y responsabilidades ${ }^{13}$. Si bien en algunos entrevistados se observa una adopción parcial de dichos valores en sus identidades laborales, para la mayoría estas nuevas formas de gestión y control organizacional suponen una exigencia cotidiana que se vive con ansiedad y temor (a perder el dinero de la caja, a no estar al tanto de las ofertas del día, a no aprender suficientemente rápido los diversos sistemas de pago y gestión), que está desprovista de un sentido personal y que no es un componente valorado y reconocido, por sí mismo y los otros, de sus identidades como trabajadores. Así, para muchos de estos sujetos, empleados de bajo nivel ocupacional, sometidos a diversas coerciones y amenazas, tratados con desconfianza e incluso desprecio, con precarias condiciones de empleo, con la sensación cotidiana de ser un recurso prescindible y reemplazable que es utilizado y explotado intensivamente, resulta bastante difícil e irreal sentirse actores responsables, reconocidos, valorados e identificados con las metas y valores de la empresa. Al igual que en los casos ya señalados de la flexibilidad en las tareas (polifuncionalidad) y en el tiempo de trabajo, la responsabilización individual resulta, así - más que un signo de un trabajo desafiante, moderno, enriquecedor y valorado- una expresión del sometimiento, la intensificación del trabajo, y el escaso reconocimiento y poder de negociación colectiva que caracteriza la experiencia laboral de los trabajadores de bajo nivel ocupacional de la sala de venta de un supermercado.

\section{Reflexiones finales}

Los tres ejes que hemos presentado, si bien en ningún caso suponen una reconstrucción exhaustiva de las condiciones de trabajo en la sala de venta de un supermercado, arrojan algunas luces respecto a ciertos aspectos de la experiencia cotidiana de los trabajadores de bajo nivel ocupacional insertos en grandes y modernizadas empresas del sector del retail en Chile. De este conjunto de hallazgos en los que hemos profundizado en este artículo nos interesa destacar a modo de conclusión tres ideas.

En primer lugar, la heterogeneidad en las condiciones y experiencias de trabajo de empleados de bajo nivel ocupacional de un supermercado. Esta constatación lleva a problematizar aquellas lecturas de los procesos de flexibilización laboral que presentan -sin atender a las múltiples diferenciaciones entre los trabajadores y los puestos de trabajo- un diagnóstico grueso, general e indiferenciado de las implicancias (positivas o negativas) de los recientes cambios laborales (De la Garza 2000, Reinecke 2006, Smith 1997). Al respecto, el aporte específico de este estudio es haber mostrado como incluso entre trabajadores de un muy similar nivel ocupacional, empleados por la misma empresa ${ }^{14}$, en el mismo espacio, e inclu- 
so en muchos casos con el mismo tipo de contrato, se producen importantes diferencias y desigualdades a nivel de la experiencia laboral producto de su inserción en una sección particular. Futuras investigaciones deberán explorar ésta y otras múltiples diferenciaciones (de género, generacionales, de formación, contractuales, etc.) que determinan diversas y muchas veces desiguales formas de experiencia laboral, contribuyendo, de este modo, a un conocimiento más preciso de la heterogeneidad de las condiciones de trabajo en las grandes empresas modernizadas del sector del retail.

En segundo lugar, la coexistencia dentro de una misma empresa de lógicas contractuales y de organización del trabajo de tipo taylorista-fordista y de tipo flexible. La modernización y flexibilización de las grandes empresas del sector retail no son procesos lineales y homogéneos, se trata más bien de cambios complejos, en diferentes niveles y temporalidades, que son objeto de problematización y resistencia por parte de distintos actores. Como ha señalado De la Garza (2000), los actuales procesos de reestructuración productiva pueden implicar cambios a nivel de las tecnologías, de la organización del trabajo, de las relaciones laborales, del perfil del trabajador y de la cultura laboral, aunque estos no necesariamente se dan simultáneamente, ni se expanden por igual en todos los ámbitos de la empresa, ni suponen necesariamente la anulación total de lógicas productivas anteriores (tradicionales, tayloristas-fordistas). Futuras investigaciones deberán explorar las particulares modalidades (niveles, ámbitos de la organización, temporalidades, etc.) en que se han llevado a cabo los procesos de reestructuración productiva en las grandes empresas del sector del retail en Chile, relevando el modo como la experiencia de los trabajadores se inscribe en marcos híbridos y complejos, que no necesariamente se ajustan a los modelos o tipos ideales de lo que es una empresa flexible. En esta tarea será fundamental atender al modo diferenciado y desigual, como lo ilustramos con el caso de las cajeras y los maestros, en que la coexistencia de lógicas e imaginarios productivos diversos (tradicionales, taylorista-fordistas, flexibles) impacta en las condiciones y la experiencia de diferentes trabajadores.

Por último, las implicancias negativas que para los trabajadores de bajo nivel ocupacional pueden estar teniendo los procesos de flexibilización laboral. Aspectos como la intensificación del trabajo, el control unilateral de los tiempos por parte de las jefaturas, los procesos de responsabilización individual y sus implicancias en términos de la transferencia de los riesgos del negocio desde la empresa al trabajador, la creciente exigencia de trabajo emocional propia del sector servicios, la gestión de los empleados como recurso barato, prescindible y polivalente en atención únicamente a las necesidades de la empresa, entre otros aspectos, dan cuenta de un escenario donde la modernización del retail, que ha conllevado beneficios para los consumidores y accionistas, ha tenido también consecuencias negativas a nivel de las forma de trabajo y de las condiciones de empleo para muchos de estos trabajadores. Si bien estos aspectos negativos aparecen con más fuerza en los relatos de cajeras, reponedores y aseadoras, no es menos cierto que son un componente transversal presente en los relatos de todos los entrevistados, incluyendo los de los “maestros” insertos en las secciones de 
mayor prestigio. Así, y a diferencia de lo que señala la retórica del new management, para muchos de los trabajadores de bajo nivel ocupacional las nuevas formas de organización y gestión flexible parecen estar asociadas, incluso en las grandes empresas, - más que a la oportunidad de acceder a un empleo moderno, estimulante, protegido, con posibilidades de capacitación, participación y promoción, con grados reales de autonomía y con mayor flexibilidad para conciliar la vida laboral y extralaboral - a una experiencia de malestar, exigencia, pérdida del control, abuso cotidiano y falta de reconocimiento que se aleja del ideal de un trabajo digno y decente (Hirsh y De Soucey 2006, OIT 2000). Esta degradación y empobrecimiento de las condiciones de trabajo y empleo de muchos de los asalariados de la próspera industria del retail es expresión, por cierto, del incremento y naturalización de la asimetría en la relación capital-trabajo que caracteriza al actual modelo de desarrollo económico en Chile, el cual ha conllevado un enorme debilitamiento del poder de negociación colectiva de los trabajadores (Lechner 2002, Garretón 2000). El estudio de este aspecto muchas veces invisibilizado de los procesos de reorganización del retail en Chile resulta un desafío académico y ético para el campo de la investigación social en Chile, una tarea ineludible en el esfuerzo por construir una sociedad más justa, democrática e inclusiva. 


\section{Notas}

${ }^{*}$ La realización de este trabajo ha sido posible gracia al financiamiento otorgado por la Universidad Diego Portales al proyecto "Construcción de vínculos sociales en un contexto de flexibilización laboral y sus implicancias para la calidad de vida y el ejercicio de ciudadanía de trabajadores y trabajadoras del sector comercio en Santiago de Chile”, Proyecto UDP $\mathrm{N}^{\circ} 090325008$.

${ }^{1}$ El retail, en su conjunto, aportó un 21,7 \% al PIB nacional el año 2006. Dentro de este sector, los supermercados concentraron un $26 \%$ del total de ventas del retail, constituyéndose en el rubro de mayor contribución (seguido de ferreterías, grandes tiendas y comercio tradicional) (Durán y Kremerman 2008).

${ }^{2}$ Una de las particularidades del desarrollo de la industria del supermercado en Chile ha sido, justamente, el claro fortalecimiento y concentración del negocio en cadenas de supermercados de propiedad nacional. Esto a diferencia de otros países de la región, donde la penetración de grandes cadenas internacionales como Carrefour o Wal-Mart ha significado desde hace ya varios años la compra y desplazamiento de las firmas locales (Gemines 1999, Lira 2005). En Chile las principales empresas del sector, D\&S y Cencosud, son (o han sido hasta hace muy poco) nacionales. De acuerdo con los datos entregados por D\&S, la participación de mercado por ventas totales en supermercados se distribuyó el año 2008 de la siguiente manera: 31.9\% D\&S, 28.9\% Censosud y 13,7\% Rendic-Saieh. (D\&S 2008). Se estima que, hasta hace muy poco tiempo, sólo un $10 \%$ de las ventas totales de los supermercados en Chile era compartida por firmas multinacionales, mientras que en otros países de la región la proporción alcanzaba un 56\% (Reardon y Berdegué 2002). Todo este escenario se está transformando con la entrada de Wal-Mart al mercado nacional a través de la adquisición de acciones emitidas por D\&S en enero de 2009. En esa fecha, Wal- Mart tomó el control de la Compañía con un 58,28\% de las acciones de la misma, porcentaje que se incrementó en el mes de marzo al 74,55\% del total de acciones emitidas por la Compañía.

${ }^{3}$ Por industria del retail (comercio al por menor) se hace referencia justamente al estrato de mayor productividad del sector, el de los grandes y modernizados grupos económicos que a través de sus redes de empresas (supermercados, tiendas por departamento, tiendas para el hogar, productos financieros, etc.) se han constituido en los actores principales y en los grandes-empleadores del sector.

${ }^{4}$ Según datos del 2006 alrededor de 1.000 .000 de trabajadores están ocupados en el sector del comercio minorista, de los cuales cerca de un $40 \%$ son trabajadores por cuenta propia. De los alrededor de 500.000 trabajadores del sector que pertenecen a la categoría de asalariados del sector privado es posible estimar que cerca de un $30 \%$ son empleados de los grandes grupos empresariales que constituyen la denominada industria del retail en Chile (Durán y Kremerman 2008, Gálvez, Henríquez y Morales 2009, MIDEPLAN 2006).

5 El objetivo general del estudio fue describir y comprender los vínculos y formas de sociabilidad que construyen los trabajadores de grandes empresas del sector comercio, analizando el modo en que dichas formas de sociabilidad inciden en la calidad de vida laboral y en las posibilidades de ejercicio de ciudadanía en el trabajo. El presente artículo se centra sólo en una parte de los hallazgos de la investigación.

${ }^{6}$ La noción de condiciones de trabajo fue utilizada en un sentido amplio y general, abarcan- 
do todos aquellos aspectos que resultaban significativos para los entrevistados a la hora de dar cuenta de su experiencia laboral. Se asumió así una definición extensa del concepto incluyendo aspectos tales como: Factores físico-ambientales, Condiciones de seguridad, Aspectos del puesto de trabajo, Carga física del trabajo, Carga mental del trabajo, Factores psicosociales (apoyo social, autonomía, relaciones personales, conductas violentas, desarrollo de habilidades, clima laboral, organización de los tiempos de trabajo, etc.), Condiciones de empleo (estabilidad contractual, salario, promoción, capacitación, participación, etc.). Conviene recordar que esta caracterización elaborada a partir de la literatura especializada (Álvaro y Garrido 2003, Blanch 2003, Goudswaard y de Nanteuil 2000, INSHT 2007, Peiró y Prieto 1996) operó sólo a nivel de un mapa general de orientación durante las entrevistas. Estas fueron de carácter semiestructurado con preguntas abiertas muy generales a partir de las cuales se buscó que los entrevistados generaran relatos -movilizando sus propias categorías, prioridades y significaciones- sobre sus experiencias y condiciones cotidianas de trabajo.

${ }^{7}$ Es importante destacar que los tres ejes que se presentan aluden a aspectos transversalmente compartidos por este grupo de trabajadores, no desarrollándose, en este artículo, aquella parte de los hallazgos que da cuenta de las diferenciaciones dentro de dicho grupo en función del género, generación, situación contractual o afiliación sindical. Cuando se alude a dichas dimensiones es únicamente en el esfuerzo de caracterizar y precisar mejor alguno de estos tres ejes.

${ }^{8}$ Por cierto que las secciones son también ámbitos internamente diferenciados, en términos de los tipos de contrato (part time o full time), de la especialización del trabajo (elaborar el pan vs vender el pan), y de las jerarquías que estas suponen ( $1^{\circ}$ operario y otros empleados de la sección). Con todo, las secciones parecen ser un principio organizador clave de la gestión, de las representaciones y de los sentidos del trabajo en la sala de venta de un Supermercado.

${ }^{9}$ No es casual que sean estas tres secciones las que habitualmente concentren la mayor cantidad de formas atípicas de empleo en los supermercados (contratos part time, suministro de trabajadores, subcontratación, contrato a plazo fijo, etc.). Con todo, es importante remarcar que en este punto nuestra argumentación se centra en las diferencias entre las secciones, más que entre los tipos de contrato. Más allá de la indudable asociación entre el estatus de las secciones y los tipos de contrato predominantes en ellas, no es menos cierto que existen ciertos aspectos de la experiencia de trabajo que dependen fundamentalmente de la inserción en una sección particular. Así, más allá de las diferencias contractuales entre las cajeras part time y full time, hay muchos aspectos comunes en su cotidianidad laboral, así como existen importantes diferencias en las condiciones de trabajo entre empleados que comparten un mismo tipo de contrato (por ejemplo un reponedor full time y un carnicero full time) pero que están insertos en secciones distintas.

${ }^{10}$ Hablando en términos muy generales es posible entender al paradigma productivo taylorista-fordista como el modelo o patrón productivo económicamente dominante en los países capitalistas más industrializados durante los treinta años posteriores a la segunda guerra mundial (Neffa 2003). Supone, en su versión idealizada, la articulación de, al menos, los siguientes elementos (Blanch 2003, Castel 1997, Neffa 1998, 2003): (i) un proceso de trabajo de tipo taylorista (estricta separación entre las actividades de concepción y ejecución, división y estandarización de las tareas en actividades simples y repetitivas, alta reglamentación y formalización de las tareas y control exterior sobre las mismas) anidado e intensificado al interior de la lógica fordista de mecanización y producción en serie en torno 
a la cadena de montaje; (ii) una organización de la producción basada en la integración vertical de la producción y en la apuesta por lograr economías de escala a través de la producción masiva y continua de bienes estandarizados, relativamente simples, idénticos entre si y habitualmente de fácil reparación y mantenimiento; (iii) un modelo de empresa y de gestión fuertemente jerárquico, centralizado, basado en la división funcional de distintas áreas y organizado desde la oferta más que desde la demanda (la gran empresa burocrática); iv) una forma de relación laboral (denominada "normal” o "fordista") caracterizada por contratos de trabajo estables, de duración indefinida y a tiempo completo; por una asignación de tareas y una duración y distribución de la jornada normada y estandarizada; por proporcionar un ingreso regular que permite la subsistencia del trabajador y su familia; y por estar inscrita en sistemas de regulación colectiva que hasta cierto punto desindividualizan y des-mercantilizan el vínculo entre el asalariado y el empleador. A estos cuatro elementos se podría agregar la presencia de (v) un particular patrón tecnológico de tipo industrial que permitió a la gran empresa fordista llevar a cabo una continua mecanización del proceso productivo a través de la incorporación de máquinas-herramientas, generalmente de propósito único, cuyo refinamiento y masificación fue posible gracias al progresivo abaratamiento y disponibilidad de fuentes de energía como la electricidad y los derivados del petróleo. Este paradigma productivo - que fue el núcleo microeconómico del régimen de acumulación y el modo de regulación fordista-keynesiano que predominó en los países desarrollados entre 1945 y 1975 - es el que habría entrado en crisis en las últimas décadas y estaría siendo reemplazado por nuevos modelos productivos (bastante heterogéneos y con implicancias muy disímiles) que tendrían en común su distanciamiento del paradigma anterior y su apuesta por la flexibilización, en uno o algunos de los cinco ejes mencionados. Para algunos autores, más que ante la emergencia de una multiplicidad de nuevos modelos productivos, estaríamos ya ante la emergencia de un único nuevo, consistente y dominante paradigma productivo de tipo flexible y mercado centrado, el cual se caracterizaría por una ruptura con el paradigma taylorista-fordista en -pensando siempre en tipos ideales- cada una de las cinco dimensiones señaladas (Harvey 1998, Todaro y Yañez 2004). Este nuevo paradigma productivo sería el núcleo microeconómico del nuevo régimen de acumulación capitalista (global-flexible-informacional) y del nuevo modo de regulación post-keynesiano de tipo neo liberal (o de liberalismo avanzado).

${ }^{11}$ Esta dinámica de control unilateral del tiempo parece ser particularmente fuerte en el caso de los trabajadores de la sala de venta que son subcontratados o que tienen contratos part time. La situación vivida por una aseadora con su empleador (empresa de limpieza que presta servicios al supermercado) ilustra con crudeza lo señalado: "El año pasado me pasó eso, que yo programé mis vacaciones para enero, cuando mis hijos salen de vacaciones, y mi jefe voy y le digo "jefe, necesito mis vacaciones en enero, para estar con mis hijos” me dice "no, te las voy a tomar mañana [era octubre]" (aseadora, empresa externa, 39 años).

${ }^{12}$ Por New Management entendemos el conjunto de nuevos discursos y prácticas de gestión empresarial que emergen en los años 80 y se consolidan en la década del 90 del siglo pasado. Distanciándose del modelo de gestión burocrático y apelando a los valores de la excelencia, la flexibilidad, la innovación y el emprendimiento individual el New Management se ha instituido en la perspectiva hegemónica respecto al modo correcto de gestionar una empresa en el nuevo escenario de globalización económica, innovación tecnológica, incertidumbre y cambio cultural. En el New Management encontramos tanto una descripción de los nuevos métodos de racionalización capitalista del trabajo propios del nuevo régimen de acumulación capitalista, como una justificación y legitimación ideológica de los mismos a partir de la apelación a un conjunto de principios y valores de orden moral (Boltanski y Chiapello 1999, Du Gay 1996). 
${ }^{13}$ La identificación con los valores de la empresa y la construcción de una identidad laboral emprendedora no necesariamente es algo positivo en sí mismo, en tanto pueden expresar el desarrollo de nuevas formas de control que restringen la autonomía de los sujetos. Como ha sido destacado por los estudios organizacionales una de las características de las nuevas formas de gestión flexible es el tránsito desde formas de control organizacional autoritarias a otras de tipo normativo (Ezzy 2001). Si las primeras, prototípicas del fordismo industrial, se fundarían en la amenaza y las recompensas explicitas que la empresa dirige a los trabajadores, las segundas, características del paradigma flexible, apuntarían a remodelar la cultura laboral y la subjetividad de los trabajadores de tal modo que éstos adopten aquellas modalidades de pensar, sentir y actuar - respecto a si mismo, los otros y la organización que sean funcionales a la empresa. Se trataría, así, de dejar atrás los sistemas de control rígidos y externos sobre la conducta del trabajador, apostando más bien por una remodelación de su identidad, de tal modo que sea el propio individuo quien, identificado con los valores y metas de la compañía, se autocontrole, autovigile y autoexiga permanentemente en el espacio laboral (Alvesson y Willmott 2002, Du Gay 1996).

${ }^{14}$ La única excepción en este punto serían las aseadoras que son contratadas por una empresa de aseo que presta sus servicios al supermercado y dos de los reponedores que eran empleados de firmas externas. 


\section{Bibliografía}

Abal, P. (2004), "Los dispositivos de control como mecanismos inhibidores de la identidad colectiva. Un estudio de caso en grandes cadenas de supermercados", en O. Battistini (Comp.), El trabajo frente al espejo. Continuidades y rupturas en los procesos de construcción identitaria de los trabajadores, Prometeo, Buenos Aires.

Abramo, L., Montero, C., y Reinecke, G. (1997), “Cambio tecnológico, encadenamientos productivos y calificaciones del trabajo en Chile: un balance, en M. Novick y M.A. Gallart (Comp.), Competitividad, redes productivas y competencias laborales: ¿Homogeneidad o segmentación?, OIT, Montevideo.

Alvaro, J.L. y Garrido, A. (2003), “Trabajo, Ocupación y Bienestar”, en Garrido, A. (Coord.), Sociopsicología del trabajo, Editorial UOC, Barcelona.

Alvesson, M. y Willmott, H. (2002), "Identity regulation as organizational control: producing the appropriate individual”, en Journal of Management Studies, 39(5), 619-644.

Ayús, R. (1999), "Supermercados: economías y culturas. Ensayo de comprensión cultural de la economía cotidiana”, en Estudios sobre las Culturas Contemporáneas, Época 5(9), 59 - 87.

Bauman, Z. (1999), Trabajo, consumismo y nuevos pobres, Gedisa, Barcelona.

Ídem (2003), Modernidad líquida, FCE, Buenos Aires.

Beck, U. (1998), ¿Qué es la globalización?, Paidós, Barcelona.

Idem (2000), Un nuevo mundo feliz: La precariedad del trabajo en la era de la globalización, Paidós, Barcelona.

Bianco, A. (2007), Wal-Mart: The Bully of Bentonville: How the High Cost of Everyday Low Prices is Hurting America, Doubleday, New York.

Blanch, J.M. (1996), “Psicología social del trabajo”. En J. L. Álvaro, A. Garrido y J. R. Torregrosa (Coord.), Psicología Social Aplicada, McGrawHill, Madrid.

Ídem (2003), Teoría de las relaciones laborales. Desafíos, Editorial UOC, Barcelona.

Boltanski, L. y Chiapello, E. (2002), El nuevo espíritu del capitalismo, Akal, Madrid. 
Castel, R. (1997), La metamorfosis de la cuestión social. Una crónica del salariado, Paidós, Buenos Aires.

Castells, M. (2001), La era de la información, Vols. I y II, Alianza, Madrid.

Calderón, A. (2006), “The expansion model of the major Chilean retail chains”, en Cepal Review, 90, 149-168.

De la Garza, E (2000), “Las teorías sobre la restructuración productiva y América Latina”, en E. De la Garza (Coord.), Tratado latinoamericano de sociología del trabajo, F.C.E, México D.F.

De Oliveira, O. y Ariza, M. (2000), “Trabajo femenino en América Latina: Un recuento de los principales enfoques analíticos”. En E. De la Garza (Coord.), Tratado latinoamericano de sociología del trabajo, F.C.E, México D.F.

Díaz, E., Ruiz Tagle, J., Aguilar, O. y Frías, P. (1999), La jornada de trabajo en el sector comercio: la experiencia en grandes tiendas, supermercados y pequeñas tiendas en malls, Dirección del Trabajo, Santiago de Chile.

Díaz, X., Godoy, L., Stecher, A. y Toro, J.P. (Coords.) (2006), Trabajo, Identidad y Vínculo Social. Reflexiones y experiencias en el capitalismo flexible, Universidad Diego Portales \& CEM ediciones, Santiago de Chile.

Díaz, X., Godoy, L. y Stecher, A. (2005), Significados del trabajo, identidad y ciudadanía: La experiencia de hombres y mujeres en un mercado laboral flexible, CEM ediciones, Santiago de Chile.

Dirección del trabajo. (2009), ENCLA 2008: Informe de Resultados Sexta Encuesta Laboral, Dirección del Trabajo, Santiago de Chile.

Du Gay, P. (1996), Consumption and Identity at Work, Sage, London.

Durán, G. y Kremerman, M. (2008), Caracterización del sector comercio al por menor (retail) Una Mirada General .Recuperado el 6 de mayo de 2008, de www.proyectoaraucaria.cl/documentos/20080205080816 informe_retail.doc

D\&S. (2008). Memoria Anual 2008. Recuperado el 12 de noviembre de 2009, de www.dys.cl/admin/upload/DyS_mem2008ESP.pdf.

Echeverría, M. y López, D. (2004), Cuaderno de Investigación $N^{\circ} 22$ : Flexibilidad laboral en Chile. Las personas y las empresas, Dirección del Trabajo, Santiago de Chile.

Ezzy, D. (2001), “A simulacrum of Workplace Community: Individualism 
and Engineered Culture”, en Sociology, 35(3), 631-650.

Faiguenbaum, S., Berdegué, J.A. y Reardon, T. (2002), “The rapid rise of supermarkets in Chile: effects on diary, vegetable, and beef chains", en Development Policy Review, 20(4), 459-471.

Gálvez, T., Henríquez, H. y Morales, G. (2009), Cuaderno de Investigación $N^{\circ}$ 36: Holding y tiendas. La trama que multiplica las ventas y redobla el trabajo, Dirección del Trabajo, Santiago de Chile.

Garretón, M.A. (2000), La sociedad en que vivi(re)mos, LOM, Santiago de Chile.

Garrido, A. (Coord.). (2003), Sociopsicología del trabajo, Editorial UOC, Barcelona.

Gemines (1997), Sector Supermercados: ¿Cómo ha evolucionado y hacia dónde va?, Gemines Consultores, Santiago de Chile.

Godoy, L.; Stecher, A. y Díaz, X. (2007), “Trabajo e identidades: continuidades y rupturas en un contexto de flexibilización laboral”, en R. Guadarrama, y J.L. Torres (Coord.) Los significados del trabajo femenino en el mundo global, Anthropos, Barcelona.

Godoy, L., y Stecher, A. (2008), "La experiencia de mujeres asalariadas en Santiago de Chile: sentidos del trabajo e identidades de género”, en B. Espinosa, (Coord.) Mundos del trabajo: pluralidad y transformaciones contemporáneas, Flacso, Quito.

Gospel, H. (2003), Quality of working life: A review on changes in work organization, conditions of employment and work-life arrangements, OIT, Ginebra.

Goudswaard, A. y de Nanteuil, M. (2000), Flexibility and Working Conditions A Qualitative and Comparative Study in Seven EU Member States, European foundation for the improvement of living and working conditions, Dublin. Harvey, D. (1998), La condición de la posmodernidad, Amorrortu, Buenos Aires.

Hirsh, P. y De Soucey, M. (2006), “Organizational Restructuring and Its Consequences: Rhetorical and Structural”, en Annual Review of Sociology, 32, 171-189.

Huberman, M. y Miles, M. (1994), "Data management and analysis methods”, en N. Denzin \& Y. Lincoln (Eds.), Handbook of Qualitative Research, Sage, California.

INSHT (2007), VI Encuesta Nacional de Condiciones de Trabajo (España), INSHT, Madrid. 
Kalleberg, A. (2001), “Organizing Flexibility: The Flexible Firm in a New Century”, en British Journal of Industrial Relations, 39(4), 479-504.

Lechner, N. (2002), Las sombras del mañana, LOM, Santiago de Chile.

Leidner, R. (1999), “Emotional Labor in Service Work”, en The ANNALS of the American Academy of political and Social Science, 561, 81-95.

Lira, L. (2005), “Cambios en la industria de los supermercados. Concentración, Hipermercados, relaciones con proveedores y Marcas Propias”, en Estudios Públicos 97, 135-160.

Macdonald, C y Sirianni, C. (Edits), (2007), Working in the service society, Temple University Press, Philadelphia.

Martuccelli, D. (2007), Cambio de rumbo. La sociedad a escala del individuo, LOM, Santiago de Chile.

MIDEPLAN (2006), Encuesta de Caracterización Socioeconómica Nacional Casen 2006, MIDEPLAN, Santiago de Chile.

Moulian, T. (1998), Chile actual, anatomía de un mito, LOM, Santiago de Chile.

Neffa, J. (1998), Los paradigmas productivos taylorista y fordista y su crisis, Lumen, Buenos Aires.

Ídem (2003), El Trabajo Humano. Contribuciones al estudio de un valor que permanece, Lumen, Buenos Aires.

OIT (2000), El trabajo decente y la reducción de la pobreza en la economía mundial, OIT, Ginebra.

Peiró, J.M y Prieto, F. (1996), Tratado de Psicología del Trabajo. Volumen I y II, Síntesis, Madrid.

PNUD (2000), Desarrollo humano en Chile, Más sociedad para gobernar el futuro, PNUD, Santiago de Chile.

Reardon, T. y Berdegué, J.A. (2002), “The rapid rise of supermarkets in Latin America: challenges and opportunities for development”, en Development Policy Review, 20 (4), 371-388.

Reinecke, G. (2006), “Is Globalization Good for Workers? Definitions and Evidence from Latin America”, en International Labor and Working-Class History 70, 11-34.

Ruiz, J.I. (2003), Metodología de la investigación cualitativa, Universidad de Deusto, Bilbao. 
Polis, Revista de la Universidad Bolivariana, Volumen 9, $N^{\circ}$ 27, 2010

Sennett, R. (2006), La cultura del nuevo capitalismo, Anagrama, Barcelona.

Smith, V. (1997), “New Forms of Work Organization”, en Annual Review of Sociology, 23, 315-339.

Soto, A. (Edit.) (2008), Flexibilidad laboral y subjetividades. LOM, Santiago de Chile.

Stecher, A.; Godoy, L. y Díaz, X. (2005), “Trabajo, identidad y vínculo social: Relaciones de producción y relaciones de género en un mundo en transformación”, en L. Schvarstein, y L. Leopold (Eds.) Trabajo y subjetividad, Paidós, Buenos Aires.

Thompson, J.B. (1990), Ideology and Modern Culture, Polity Press, Cambridge.

Todaro, R. \& Yáñez, S. (Edits.) (2004), El trabajo se transforma. Relaciones de producción y relaciones de género, Cem ediciones, Santiago de Chile

Wagner, P. (1997), Sociología de la modernidad, Herder, Barcelona.

Recibido: 22.11.2009

Aceptado: 05.05.2010 